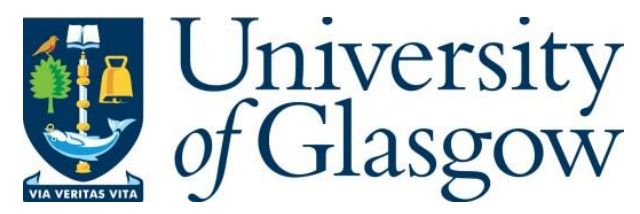

Zhang, P., Xing, X., Wang, Y., Murtaza, I., He, Y., Cameron, J., Ahmed, S., Skabara, P. J. and Meng, H. (2019) Multi-colour electrochromic materials based on polyaromatic esters with low driving voltage. Journal of Materials Chemistry C, 7(31), pp. 9467-9473. (doi: 10.1039/C9TC02919B)

There may be differences between this version and the published version. You are advised to consult the publisher's version if you wish to cite from it.

http://eprints.gla.ac.uk/190866/

Deposited on: 8 August 2019

Enlighten - Research publications by members of the University of Glasgow http://eprints.gla.ac.uk 


\title{
Multi-colour Electrochromic Materials Based on Polyaromatic Esters with Low Driving Voltage
}

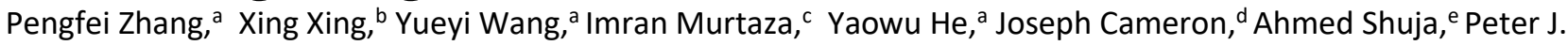
Skabara $^{\mathrm{d}}$ and Hong Meng*a


China.

${ }^{b}$ Research \& Development Institute of Northwestern Polytechnical University (Shenzhen), Northwestern Polytechnical University, Shenzhen 518057, China

cDepartment of Physics, International Islamic University, Islamabad 44000, Pakistan.

dUniversity of Glasgow, School of Chemistry, Joseph Black Building, University Place, Glasgow, G12 8QQ, United Kingdom.

${ }^{\mathrm{e}}$ Centre for Advanced Electronics \& Photovoltaic Engineering (CAEPE), International Islamic University, Islamabad 44000, Pakistan

\begin{abstract}
Low-cost single molecular electrochromic (EC) materials with low toxicity are desirable for EC displays and photonic devices. In this study, new EC materials based on phthalates, an inexpensive class of benzoate materials with relatively simple molecular structure are designed and prepared. Despite being good candidates for EC devices due to clear colour change when reduced, devices fabricated using phthalate derivatives (PDs) suffer from a high driving voltage. Herein, we propose a facile strategy of replacing the benzene core with polyaromatic esters to enlarge the conjugated area and to synthesis PDs to lower the driving voltage in the EC devices. Additionally, the devices show a good memory effect, the ability to undergo multiple colour changes and enhanced stability, dependent on the size of the conjugated bridge between the two sides of the molecule. The fabricated EC devices based on polyaromatic esters demonstrate low driving voltage $(-2.6 \mathrm{~V})$ and good memory effect (hundreds of seconds). We have shown that the number of aromatic ester rings in the conjugated area is very critical to obtain different colours in this new class of EC materials. This series of EC materials has a promising potential for future industry applications due to the vivid colour change upon electrochemical stimulation at a low driving voltage.
\end{abstract}

Key words: Electrochromic, stability, low driving voltage, multi-colour, memory effect. 


\subsection{INTRODUCTION}

Organic electrochromic (OEC) materials have provoked great interest in the past few decades, because of their low energy consumption, vivid and facile colour change through molecular design and large-scale integration. ${ }^{1-5}$ Electrochromic materials constitute either conducting polymers ${ }^{3,5,6}$ or small molecular materials. ${ }^{1,2}$ While devices made using electrochromic polymers (ECPs) generally show better stability and lower driving voltage, a colourless transparent state and widening the colour gamut are more easily achieved in small molecular OEC materials., Additionally, small molecules are inexpensive due to their facile synthesis. ${ }^{2}$ Since the first report of viologens by Schoot et al. in 1973, ${ }^{7}$ many single molecular OECs have been developed, including phthalates,${ }^{8}$ thiophenes ${ }^{9}$ and anthraquinones. ${ }^{10,11}$ Among them, phthalate derivatives (PDs) are extremely low-cost and environmentally friendly compared to other candidates. In 1987, a series of PDs reported showed vivid colour change in response to a change in voltage. ${ }^{8}$ However, it was not until 2008 that this was further studied by Sharmoukh et al. It was proposed that the electrochromism in isophthalates occurs via one-electron reduction, to form radical anions ${ }^{12}$ as well as through a two-electron reduction, to form di-anions, which makes them more stable than single anionic radical species. ${ }^{13}$ Their work enriched the colour gamut, but the driving voltage was still high for practical application. Therefore, the development of PDs based devices with low driving voltage remains a challenge which needs to be addressed.

One of the most effective methods to reduce the driving voltage of PDs based devices is utilisation of a polymer electrolyte instead of solution, ${ }^{14}$ in addition to four other reported methods: (i) introducing heterocycle compounds, such as: thiophene, ${ }^{15} \mathrm{Azo}^{16}$ or pyridine, ${ }^{17}$ which usually bring colour to the neutral state of PDs. (ii) Grafting them to microspheres or modified electrode, which impacts the colour switching performance ${ }^{18}$. (iii) The introduction of ferrocene to the solution ${ }^{19}$ and (iv) the use of a modified electrodes. ${ }^{14}$ However, there is still a great need to work on the molecular design aspect of new PDs. 
In this study, we propose a facile molecular design strategy for PDs, to lower the driving voltage, increase the stability with good memory effect (hundreds of seconds) and induce multicolour switching. The strategy is to combine aromatic (Ar) units to increase the conjugated area of the molecule. ${ }^{13}$ In particular, Polyaromatic esters are prepared easily by the reaction of polyaromatic anhydride and ethanol, in the presence of concentrated sulfuric acid as a catalyst, or the reaction of polyaromatic anhydride and 1-bromobutane, in the presence of aqueous sodium hydroxide solution acid and trioctylmethylammonium chloride. The electrochromic colours can be tuned by variation in the conjugated areas of polyaromatic group, enabling rich and multi-electrochromism in the reduced state and transparent colourless appearance in the neutral state. Additionally, the stability, memory effect and driving voltage of the PDs with larger conjugated areas is better than those with the smaller area.



\subsection{Experimental section:}

Synthesis routes: 


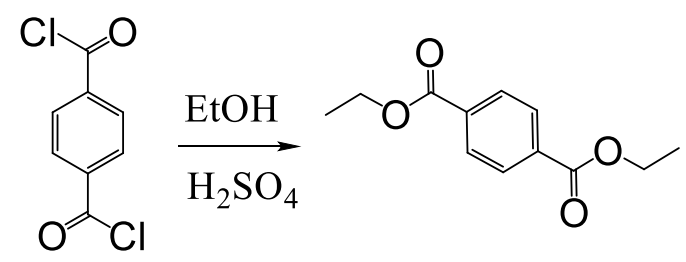

Scheme 1. The synthesis route of DTP

Synthesis of diethyl terephthalate (DTP) (Scheme 1): Benzoyl chloride (0.01 mol) was slowly added to a stirred solution of ethanol $(100 \mathrm{~mL})$, and $5 \mathrm{ml}$ of $\mathrm{H}_{2} \mathrm{SO}_{4}$ was added dropwise. The mixture was stirred at room temperature for 6 hours. After completion of the reaction, a saturated $\mathrm{NaHCO}_{3(\mathrm{aq})}$ solution was added. Then the product was extracted by ethyl acetate and washed with deionised water, then the organic phase was treated with anhydrous $\mathrm{Na}_{2} \mathrm{SO}_{4}$ to remove water. The solution was filtered and solvent evaporated to obtain the product as a white powder. (2.0 g, yield: 90\%). ${ }^{1} \mathrm{H}$ NMR (400 MHz, DMSO-d6) $\delta 8.08(\mathrm{~s}, 4 \mathrm{H}), 4.35(\mathrm{q}, J=7.1 \mathrm{~Hz}, 4 \mathrm{H}), 1.34(\mathrm{t}, J=7.1 \mathrm{~Hz}$, $6 \mathrm{H}) .{ }^{13} \mathrm{C}$ NMR (101 MHz, DMSO- $\left.d_{6}\right) \delta 165.00,133.72,129.42,61.24,38.95,14.09$. HRMS (ESI) $m / z:[\mathrm{M}+\mathrm{H}] .^{+}$(calcd for $\mathrm{C}_{22} \mathrm{H}_{15} \mathrm{O}_{4}, 223.0970$; found, 223.0964). Data consistent with literature. ${ }^{20}$

<smiles>CCOC(=O)c1cc(C(=O)OCC)c(C(=O)OCC)cc1C(=O)OCC</smiles>

Scheme 2. The synthesis route of TBTC

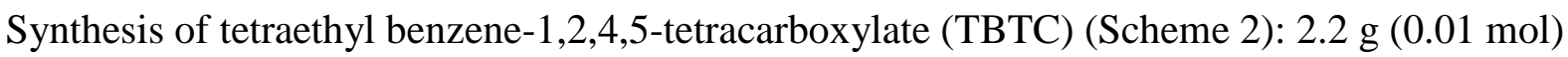
of pyromellitic dianhydride was added to $50 \mathrm{ml}$ of ethanol in a round bottom flask with condenser under stirring. The solution was then heated to $100{ }^{\circ} \mathrm{C}$, and $5 \mathrm{ml}_{\text {of }} \mathrm{H}_{2} \mathrm{SO}_{4}$ was added to the mixture dropwise for 4 hours before allowing the mixture to cool down to room temperature. A saturated solution of $\mathrm{NaHCO}_{3(\mathrm{aq})}$ was then added to the mixture until no bubbles were present. The product was then extracted with ethyl acetate, washed with deionised water and treated with anhydrous $\mathrm{Na}_{2} \mathrm{SO}_{4}$ to remove water. The solvent was removed on a rotary evaporator to give the product as a white solid. (2.5 g, yield: 68\%). ${ }^{1} \mathrm{H}$ NMR (500 MHz, DMSO- $\left.d_{6}\right) \delta 8.07$ (s, 2H), $4.32(\mathrm{~d}, J=7.1$ $\mathrm{Hz}, 8 \mathrm{H}), 1.30(\mathrm{t}, J=7.1 \mathrm{~Hz}, 12 \mathrm{H}) .{ }^{13} \mathrm{C}$ NMR $\left(101 \mathrm{MHz}, \mathrm{DMSO}-d_{6}\right) \delta 165.27,133.93,129.05$, 
62.06 , 13.79. HRMS (ESI) m/z: [M + Na] ${ }^{+}$(calcd for $\mathrm{C}_{18} \mathrm{H}_{22} \mathrm{NaO}_{8}, 389.1213$; found, 389.1205).

<smiles>[R]OC(=O)C1CCC(C(=O)O[R])C(C(=O)O[R])CCC1[In]</smiles>

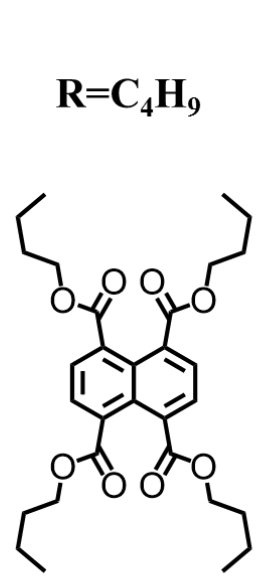

TNTC

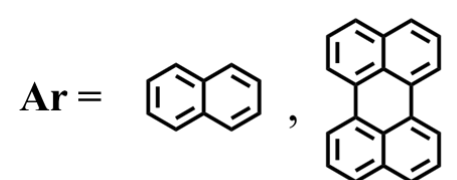

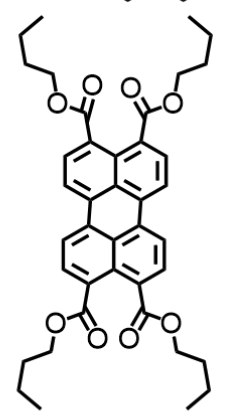

TPTC

Scheme 3. The synthesis route of TNTC and TPTC

Synthesis of tetrabutyl naphthalene-1,4,5,8-tetracarboxylate (TNTC) (Scheme 3): $2.68 \mathrm{~g}(0.01$ mol) of 1,4,5,8-Naphthalenetetracarboxylic dianhydride was added to $100 \mathrm{ml}$ of $\mathrm{NaOH}(1 \mathrm{M})$, and after stirring for 5 minutes, the round bottom flask was heated to $100{ }^{\circ} \mathrm{C}$, stirred for 0.5 hour to completely dissolve the solvents, and then 1-bromobutane $(10 \mathrm{~g}, 0.073 \mathrm{~mol})$ and trioctylmethylammonium chloride $(2 \mathrm{~g} .0 .05 \mathrm{~mol})$ was added to the mixture. The mixture was heated to $140{ }^{\circ} \mathrm{C}$ and allowed to react for 4 hours before being cooled to room temperature. The resulting precipitate was filtered and washed with deionised water. Elution with ethyl acetate and ethanol and subsequent evaporation gave pale yellow crystals (3.9 g, yield:74\%). ${ }^{1} \mathrm{H}$ NMR (500 MHz, DMSO-d 6$) \delta 8.08(\mathrm{~s}, 4 \mathrm{H}), 4.25(\mathrm{t}, J=6.7 \mathrm{~Hz}, 8 \mathrm{H}), 1.68(\mathrm{p}, J=6.9 \mathrm{~Hz}, 8 \mathrm{H}), 1.47-1.32(\mathrm{~m}$, 8H), $0.92(\mathrm{t}, J=7.4 \mathrm{~Hz}, 12 \mathrm{H}) .{ }^{13} \mathrm{C}$ NMR $\left(126 \mathrm{MHz}, \mathrm{DMSO}-d_{6}\right) \delta 167.10,133.03,129.22,127.87$, 65.20, 39.04, 29.97, 18.63, 13.57. HRMS (ESI) $m / z:[\mathrm{M}+\mathrm{Na}]^{+}\left(\right.$calcd for $\mathrm{C}_{30} \mathrm{H}_{40} \mathrm{NaO}_{8}, 551.2615$; found, 551.2617).

Synthesis of tetrabutyl perylene-3,4,9,10-tetracarboxylate (TPTC) (Scheme 3): 3,4,9,10- 
Perylenetetracarboxylic dianhydride, $3.9 \mathrm{~g}(0.01 \mathrm{~mol})$, was added into $100 \mathrm{ml}$ of $\mathrm{NaOH}(1 \mathrm{M})$ under stirring in a round bottomed flask and heated to $100{ }^{\circ} \mathrm{C}$ under constant stirring for $0.5 \mathrm{~h}$ to totally dissolve the constituents. Then, 1-bromobutane $\left(\begin{array}{llll}10 & \mathrm{~g}, & 0.073 \mathrm{~mol}\end{array}\right)$ and trioctylmethylammonium chloride $(2 \mathrm{~g}, 0.05 \mathrm{~mol})$ were added, respectively, into this mixture. The mixture was heated to $140{ }^{\circ} \mathrm{C}$ and allowed to react for $4 \mathrm{~h}$. After allowing the mixture to cool down to room temperature, the precipitate was filtered and washed using deionized water, ethyl acetate and ethanol to obtain orange powder. (4.8 g, yield:74\%). ${ }^{1} \mathrm{H}$ NMR (500 MHz, Benzene- $\left.d_{6}\right)$ $\delta 8.02(\mathrm{~d}, J=7.8 \mathrm{~Hz}, 4 \mathrm{H}), 7.58(\mathrm{~d}, J=7.9 \mathrm{~Hz}, 4 \mathrm{H}), 4.42(\mathrm{t}, J=6.8 \mathrm{~Hz}, 8 \mathrm{H}), 1.81-1.60(\mathrm{~m}, 8 \mathrm{H})$, $1.44-1.31(\mathrm{~m}, 8 \mathrm{H}), 0.86(\mathrm{t}, J=7.4 \mathrm{~Hz}, 12 \mathrm{H}) .{ }^{13} \mathrm{C}$ NMR $\left(126 \mathrm{MHz}\right.$, Benzene- $\left.d_{6}\right) \delta 168.55,133.30$ 131.33, 130.55, 129.58, 129.22, 121.64, 65.30, 31.09, 19.63, 13.94. HRMS (ESI) $m / z:[\mathrm{M}+\mathrm{Na}]^{+}$ (calcd for $\mathrm{C}_{40} \mathrm{H}_{44} \mathrm{NaO}_{8}, 675.2934$; found, 675.2948).

UV-Vis-NIR absorption spectra were recorded using a UV-Vis-NIR Perkin Elmer LAMBDA 750 spectrophotometer in a quartz cuvette. CV electrochemistry experiments were performed using a Gamry Interface 1000E potentiostat/galvanostat.

\subsection{RESULTS AND DISCUSSION}

\subsubsection{EC behaviour of DTP, TBTC, TNTC and TPTC solutions:}

Firstly, the novel materials were characterised using cyclic voltammetry and UV/Vis spectroscopy. The cyclic voltammograms in Figure 1 (a) show reversible redox waves between +0.2 and $-3.0 \mathrm{~V}$ vs. $\mathrm{Ag} / \mathrm{Ag}+$. Two reversible and separated redox peaks are observed for all the four synthesised compounds, suggesting all of them have the potential to possess a multicolour switching characteristic. Meanwhile, the applied redox potentials of TBTC, TNTC and TPTC are lower than the reported isophthalate-based EC compound(2.0-2.7V as Table S1 shows). ${ }^{12}$ TBTC, TNTC and TPTC all show the two-step reduction processes with the first one-electron reversible reduction peaks at $-1.87,-1.92$ and $-1.50 \mathrm{~V}$, and the second two-electron reversible reduction peaks at $-2.42,-$ 


\subsection{7 and $-1.84 \mathrm{~V}$, respectively.}

The designed and synthesised polyaromatic ester derivatives, TBTC, TNTC and TPTC are based on conjugated rings of benzene, naphthalene and perylene, respectively, in order to determine the influence of the size of conjugated core on the electrochromic properties. Depending on the size of the conjugated area, as shown in Figure 1 (b), the three compounds show different colours in their neutral states. Benzene and naphthalene being smaller in size, as compared to perylene, show a colourless neutral state whereas the perylene derivative, TPTC, shows a yellow neutral state. Based on the CV scans and UV-Vis spectroscopy, different parameters related to the optoelectronic properties of all four compounds were calculated and summarised in table 1 . The results show that our facile design strategy has been successful to obtain deeper LUMO levels and lower reduction potentials, for TBTC, TNTC and TPTC compared to DTP, which is desirable for good OEC materials. The schematic of the solution test process is shown in S2.
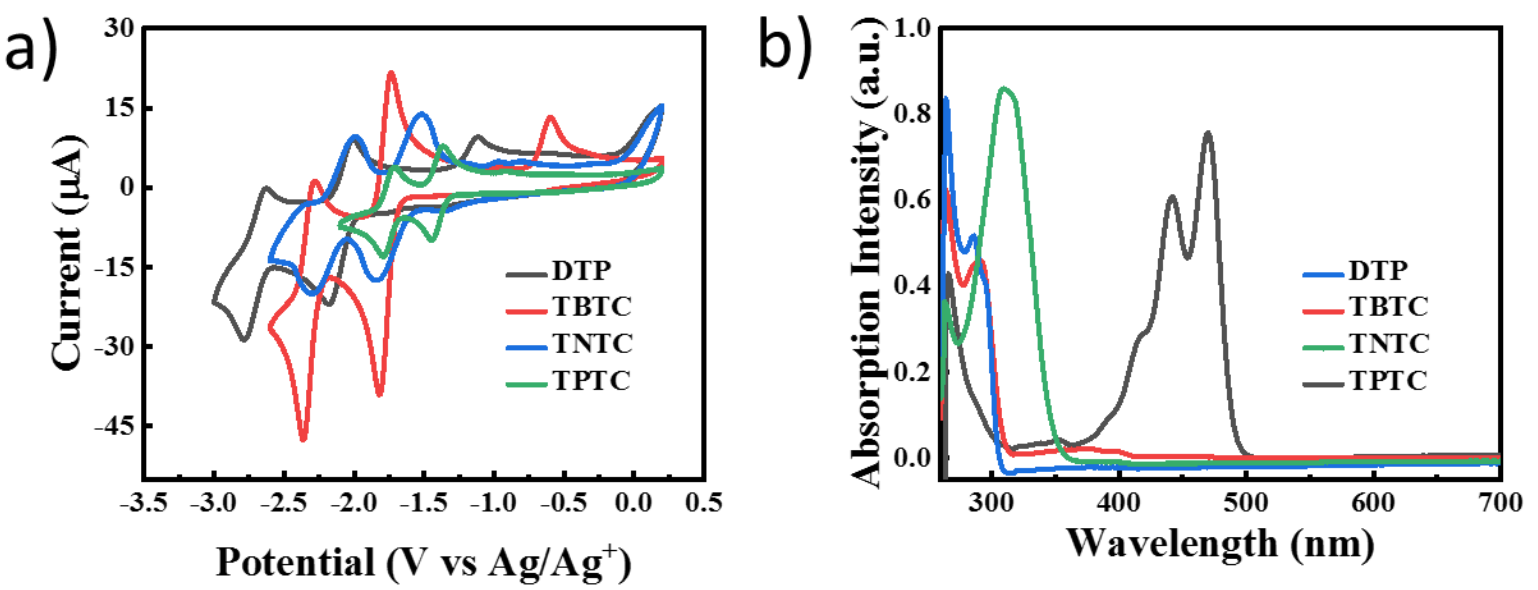

Figure 1. (a) Cyclic voltammograms and (b) UV-Vis absorption spectra of DTP, TBTC, TNTC and TPTC. (CV: three-electrode system: WE-glassy carbon electrode; $\mathrm{CE}-\mathrm{Pt}$ wire; $\mathrm{RE}-\mathrm{Ag} / \mathrm{Ag}^{+}$, scan speed: $100 \mathrm{mV} / \mathrm{s}$, solution: $0.1 \mathrm{mM}$ anhydrous DMF with $0.15 \mathrm{M} \mathrm{TBAPF}_{6}$ ); (UV-vis: Anhydrous DMF solution) 
Table 1. Optical and Electrochemical Properties and Corresponding Energy Levels of DTP, TBTC, TNTC and TPTC. (Three-electrode system: WE-glassy carbon electrode; CE-Pt wire; RE-Ag/Ag ${ }^{+}$)

\begin{tabular}{|c|c|c|c|c|c|c|c|c|}
\hline & \multirow{2}{*}{$\begin{array}{c}\lambda_{\max }[\mathrm{nm}] \\
\text { in DMF }\end{array}$} & \multirow{2}{*}{$\begin{array}{c}\lambda_{\text {onset }}^{\text {a) }} \\
{[\mathrm{nm}]}\end{array}$} & \multirow{2}{*}{$\begin{array}{l}\mathbf{E}_{\mathrm{g}}^{\mathbf{b})} \\
{[\mathrm{eV}]}\end{array}$} & \multirow{2}{*}{$\begin{array}{l}\mathbf{E}_{\mathbf{r e}}, \\
\text { onset } \\
{[\mathbf{V}]}\end{array}$} & \multirow{2}{*}{$\begin{array}{c}\mathbf{E}_{\text {LUMo }}{ }^{\mathrm{c})} \\
{[\mathrm{eV}]}\end{array}$} & \multicolumn{2}{|c|}{$\begin{array}{c}\text { Reduction Potential }^{\mathrm{d})} \\
(\mathrm{V}, \text { vs. Fc/Fc }(\mathbf{A g} / \mathbf{A g}+))\end{array}$} & \multirow{2}{*}{$\begin{array}{c}\text { Energy gap } \\
\text { between two } \\
\text { reduced state }(\mathrm{V}) \\
(\mathrm{CV}) \\
\end{array}$} \\
\hline & & & & & & $\begin{array}{l}\text { First } \\
\text { (ON1) }\end{array}$ & $\begin{array}{l}\begin{array}{l}\text { Second } \\
\text { (ON2) }\end{array} \\
\end{array}$ & \\
\hline DTP & $286 / 264$ & 313 & 3.96 & -2.00 & -2.80 & $\begin{array}{l}-2.25 \\
(-2.19)\end{array}$ & $\begin{array}{l}-2.86 \\
(-2.80)\end{array}$ & 0.61 \\
\hline TBTC & $291 / 264$ & 415 & 2.99 & -1.66 & -3.14 & $\begin{array}{l}-1.87 \\
(-1.81)\end{array}$ & $\begin{array}{c}-2.42 \\
(-2.36)\end{array}$ & 0.55 \\
\hline TNTC & $309 / 263$ & 370 & 3.35 & -1.57 & -3.23 & $\begin{array}{l}-1.92 \\
(-1.86)\end{array}$ & $\begin{array}{c}-2.37 \\
(-2.31)\end{array}$ & 0.45 \\
\hline TPTC & $\begin{array}{c}470 / 441 / \\
266\end{array}$ & 520 & 2.38 & -1.33 & -3.47 & $\begin{array}{l}-1.50 \\
(-1.44)\end{array}$ & $\begin{array}{c}-1.84 \\
(-1.78)\end{array}$ & 0.34 \\
\hline
\end{tabular}

a) Measured in anhydrous DMF solution;; b) $\mathrm{Eg}=1240 / \lambda$ onset ; c) ELUMO = - (Ere,onset + 4.8) $\mathrm{eV}$; d) Redox potential vs $\mathrm{Fc} / \mathrm{Fc}+, 0.15 \mathrm{M}$ Tetra-n-butylammonium hexafluorophosphate as supporting electrolyte in $\mathrm{DMF}, \mathrm{Ag} / \mathrm{Ag}+$ as reference electrode, glassy carbon as the working electrode and platinum as the counter electrode.

The EC behaviours of the four compounds (DTP, TBTC, TNTC and TPTC) were initially tested using solution-state spectroelectrochemistry (Figure $2 \mathrm{a}-\mathrm{d}$ ). The applied potentials are reported with respect to $\mathrm{Ag}$ wire quasi-reference electrode as a $\mathrm{Ag} / \mathrm{Ag}+$ reference electrode is not compatible with the experimental setup of the spectrophotometer. In the neutral state, the four compounds, tested in anhydrous DMF solution, show a strong absorption around $264 \mathrm{~nm}$ (UV region) which is consistent with the absorption spectra of methyl benzoate, ${ }^{21}$ as this absorption corresponds to the benzene bands: $1 \mathrm{Lb} \leftarrow 1 \mathrm{~A}\left(\lambda_{\max }(1 \mathrm{Lb})=256 \mathrm{~nm}, \varepsilon=200 \mathrm{M}^{-1} \mathrm{~cm}^{-1}\right.$, showing a regular vibrational structure. The other absorption peaks for TBTC and DTP appear at $286 \mathrm{~nm}$. Where there is a naphthalene core instead of benzene, the absorption peak shows a bathochromic shift to $309 \mathrm{~nm}$ and its intensity is also enhanced. For the perylene derivative there is a further bathochromic shift to around $470 \mathrm{~nm}$.

The applied potential is gradually increased for DTP until at $-1.5 \mathrm{~V}$, a new absorption peak arises at $538 \mathrm{~nm}$, due to the reduction of DTP, and the solution becomes pink. In TBTC, absorption 
peaks emerge at 536 and $375 \mathrm{~nm}$ with the application of a lower potential $(-1.1 \mathrm{~V})$. This is due to formation of its first reduced state, and the solution becomes magenta in colour. At a higher potential $(-1.7 \mathrm{~V})$, an absorption peak arises at $430 \mathrm{~nm}$ and the intensities of the peaks at 536 and $375 \mathrm{~nm}$ decrease as TBTC is further reduced to a second reduced state and the solution turns yellow. The first reduced state of DTP and TBTC have a similar absorption peak suggesting that the same core influences this peak. However, TBTC has a stronger intensity of low energy peak compared to that of DTP, so we can attribute the absorption at $536 \mathrm{~nm}$ to the radical anion while the peak at $375 \mathrm{~nm}$ is characteristic of the benzene core. Therefore, the increased number of ester groups in TBTC causes an increase in the intensity of the absorption peak at $536 \mathrm{~nm}$. And the colour of TBTC appears more red than DTP.

The first reduced state of TNTC occurs at a lower potential of $-1.1 \mathrm{~V}$ and absorption peaks are observed at 533 and $438 \mathrm{~nm}$, giving the solution a yellow colour. When the applied potential is increased, the absorption at $533 \mathrm{~nm}$ is enhanced, causing the solution to become red. At a higher potential (-1.6V), the absorption peak at $402 \mathrm{~nm}$ and a broad absorption in the range $600-750 \mathrm{~nm}$ is observed. The absorption peaks at 533 and $438 \mathrm{~nm}$ gradually decrease as the applied potential increases due to formation of the second reduced state of TNTC and the solution shows a dark red colour.

TPTC shows a strong absorption in the range $370-496 \mathrm{~nm}$. Therefore, the absorption spectra were recorded in much more diluted solution of TPTC $(10 \mu \mathrm{M})$, to explore the evolution of this peak as a function of applied potentials as shown in Figure S2, through the set up as shown in Figure S4. It shows at different potential, the absorption intensity from $400 \mathrm{~nm}$ to $500 \mathrm{~nm}$ has little change, meaning the electrochromic phenomenon of TPTC mainly depends on the evolution of the absorption around $650 \mathrm{~nm}$ as shown in Figure $2 \mathrm{~d}$. At $-0.3 \mathrm{~V}$, an absorption peak exists at $637 \mathrm{~nm}$, which is attributed to the first reduced state of TPTC, and the solution shows a bright green colour. At a higher potential of -2.1V (Figure S3), the absorption peak intensity at $637 \mathrm{~nm}$ begins to decrease, 
due to formation of the second reduced state of TPTC with the solution turning to orange. A further increase in applied potential, the solution causes stronger absorption in the visible region, resulting dark-yellow colour being formed. All the materials have a longer absorption wavelength at the first reduced state than that at the second reduced state. The strong absorption peak and the PL emission peak of TPTC are stable, when applied potential is changing. Moreover, it is clearly observed that an increase in the area of the conjugated ester causes a decrease in the driving voltage, which is an important finding of this study.

a)

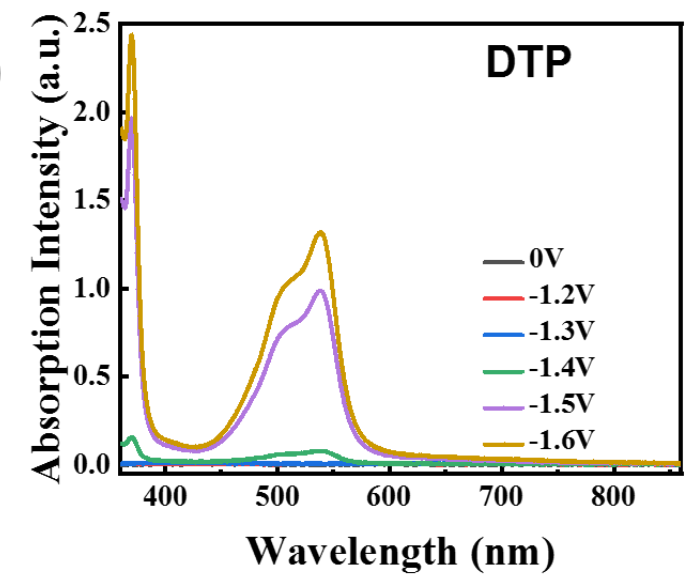

c)

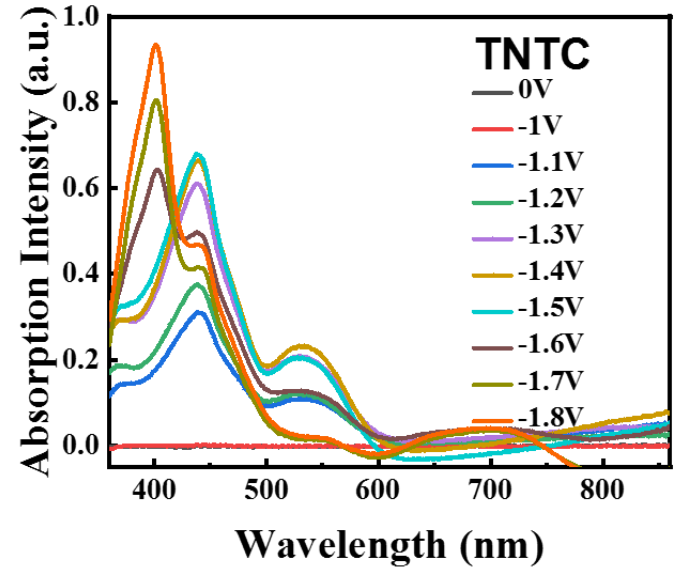

b)

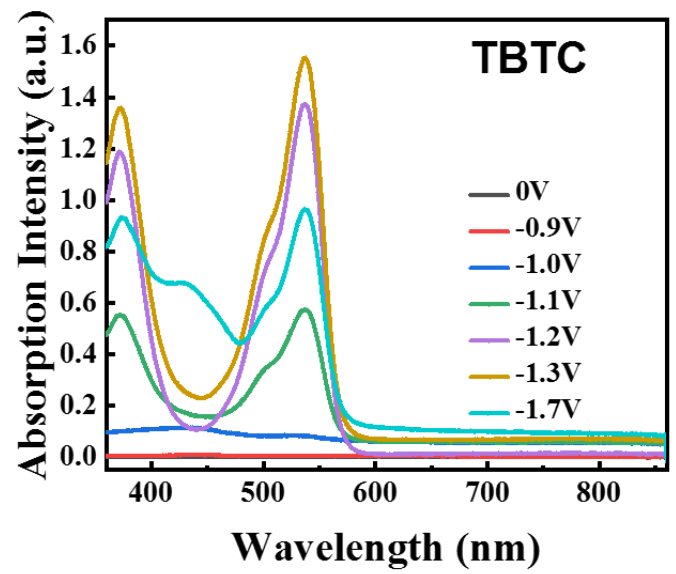

d)

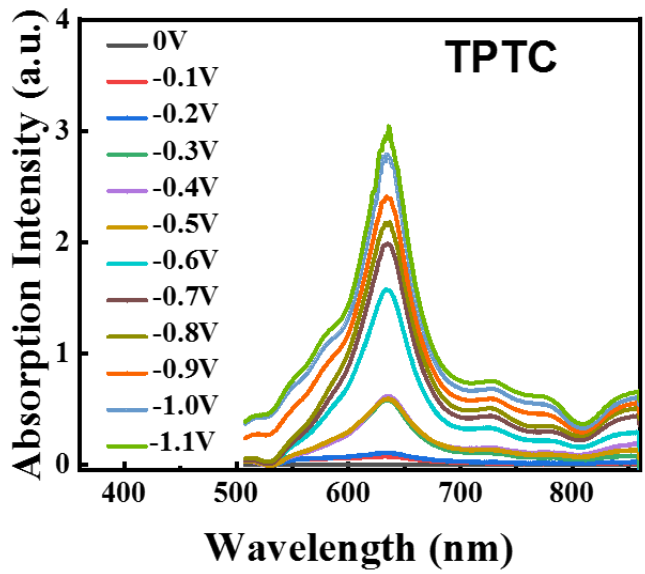

Figure 2. Spectroelectrochemistry of DTP, TBTC, TNTC and TPTC in anhydrous DMF solution (1 mM DTP, TBTC, TNTC and TPTC; TBAP(Tetra-n-butylammonium perchlorate) (5 mM)) (UV$\mathrm{Vis}$ spectra were taken at $0 \mathrm{~V}$ as background for all tests). Three-electrode system: WE-Pt-mesh; CE-Pt wire; RE-Ag wire. 


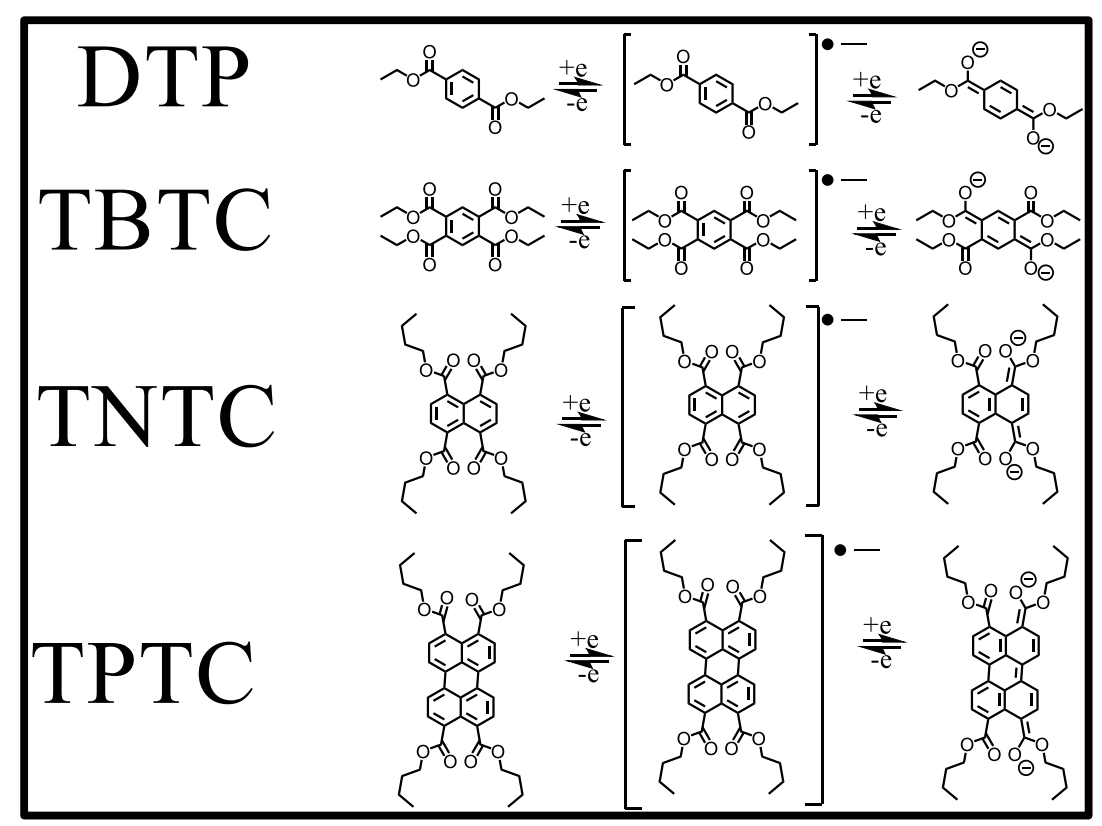

Figure 3. Structures of the reduced forms of DTP, TBTC, TNTC and TPTC.

The structures of the reduced species of the four molecules are shown in Figure 3. Compared with DTP, the new compounds, TBTC, TNTC and TPTC, have two colourful reduced states, due to their tetra-ester structure. This endows multicolour characteristics to the three newly designed compounds.

\subsubsection{Electrochromic Devices:}

Figure $4 \mathrm{a}$ shows the photographs of the colour displayed by all the synthesised compounds at different voltages and the simple structure of the fabricated electrochromic cell is shown in Figure 4b. The electrochromic cells were fabricated by injecting the respective anhydrous solutions of the EC materials in between the two ITO-coated glass electrodes, secured with Surlyn ${ }^{\circledR}$ tape. Four solutions were obtained by dissolving the respective compounds ( $25 \mathrm{mM}$ for DTP, TBTC, TNTC and $2 \mathrm{mM}$ for TPTC) and tetrabutlammonium hexafluorophosphate (TBAP) (50 mM) in anhydrous DMF. Figure 4a demonstrates that along with the increase in the conjugation of the three compounds, the driving voltage decreases significantly. TPTC displays a bright green colour when applied potential is only $-2.6 \mathrm{~V}$. Furthermore, all the EC materials completely recover their original state when the applied potential is removed. Additionally, the enlargement in the conjugated area causes enhanced memory effect of EC materials, just as molecular design prediction and it has been recorded in a short video (supplementary videos). It is observed that the memory effect improves with increases conjugation area. Interestingly, Sharmoukh and co-workers ${ }^{13}$ reported a series of 
molecules where the memory effect reduced with increasing conjugation length. The difference in these observations can be explained due to the structural differences. In the Sharmoukh series of molecules, the bis-isophthalate derivative was shown to form a relatively stable, flat, quinoidal structure. However, it is likely that with increasing phenylene chain length some twisting will occur even in the dianion form, making the species more short-lived. However, the novel materials we have reported are rigid, fused systems. Therefore, from these observations we propose that increasing the conjugation area of PDs leads to improved memory effect with stabilisation of the dianionic species due to the planar fused core and though resonance. Additionally, the position of the ester groups in the path of conjugation will contribute to the stabilisation. 


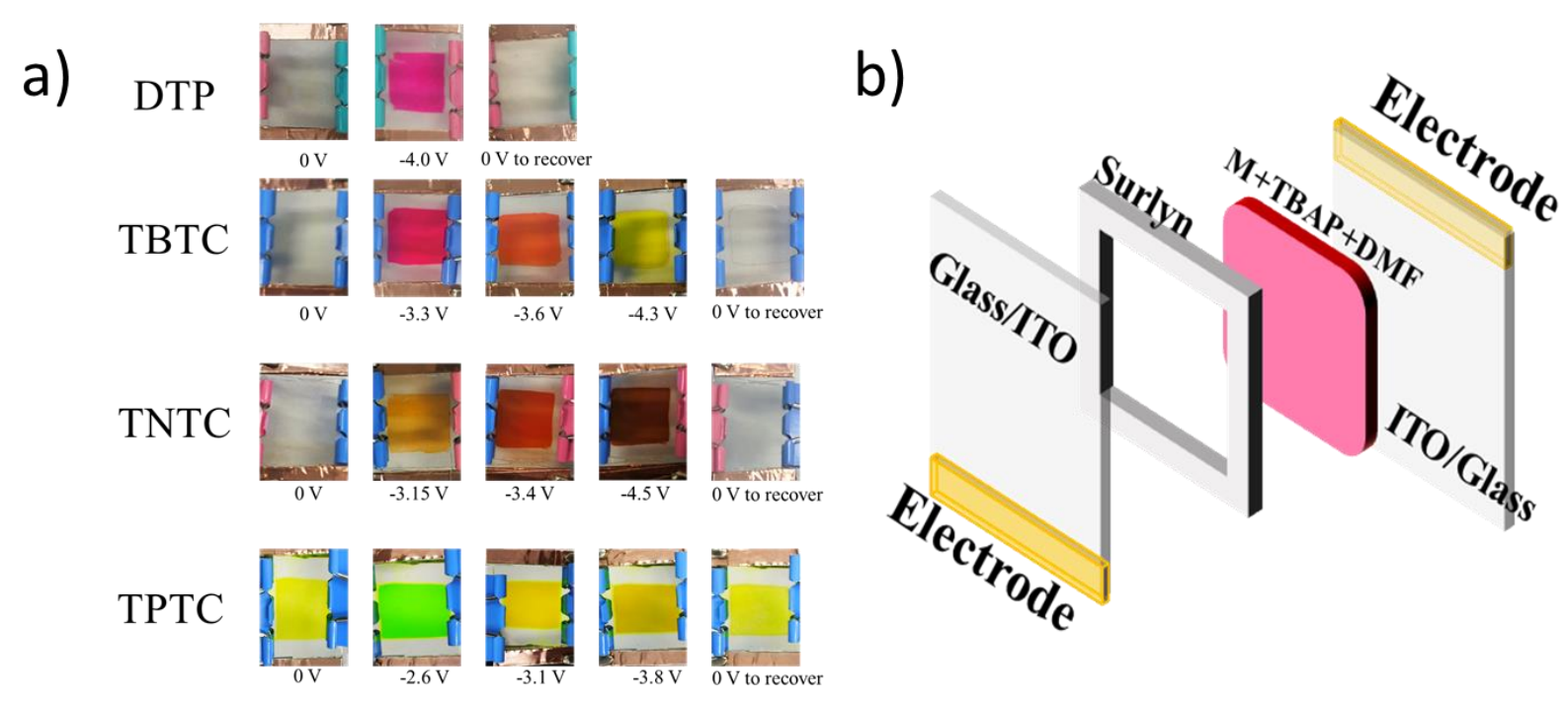

Figure 4. (a) Photographs of the displayed colours of DTP, TBTC, TNTC and TPTC at different applied potential. (b) Schematic diagram of the Simple device structure of the electrochromic cells. Device size: $20 \mathrm{~mm} \times 20 \mathrm{~mm} \times 1 \mathrm{~mm}$. solution for TPTC: $2 \mathrm{mM}$ TPTC $+50 \mathrm{mM}$ TBAP in anhydrous DMF solution. Other materials: $25 \mathrm{mM} \mathrm{W}+50 \mathrm{mM}$ TBAP in anhydrous DMF solution.

\subsubsection{Electrochromic memory effect and stability:}

The charge transfer behaviour in DTP, TBTC, TNTC and TPTC solutions was analysed by the change in transmission, as shown in Figure S5, S6, S7 and S8. Continuous changes of pulse width were given to DTP, TBTC, TNTC and TPTC solutions and their respective transmittance changes at $538 \mathrm{~nm}, 536 \mathrm{~nm}, 438 \mathrm{~nm}$ and $637 \mathrm{~nm}$ were monitored, respectively. The contrast of these materials, in solution in the visible region, is summarised in Table S2. The overall trends show that, compared to DTP, the three compounds TBTC, TNTC and TPTC have a good memory effect which increases with larger conjugation area, although this contributes to a lower colouring efficiency. The stability and memory effects were calculated for the first reduced state so the discussion is focused accordingly. The increased number of electron withdrawing ester groups in TBTC assists in stabilisation of the reduced form. Furthermore, the increase in conjugated area of TNTC and TPTC leads to further stabilisation.

The stability of TBTC, TNTC and TPTC increases with the enlargement in their conjugated areas. As shown in Figure S9, the transmittance stability tests of DTP, TBTC, TNTC and TPTC solutions 
in air were performed over 80 cycles, indicating that the stability increases with increasing molecular size. Additionally, TPTC, TNTC and TBTC, which are tetra-esters, are more stable than DTP, a normal double-ester. This proves that extending the conjugated areas and replacing the double-ester with tetra-esters are effective ways to achieve better stability.

The stability of the solutions was also tested in a dry box to eliminate any instability that can be attributed to air or moisture. Each compound was analysed by repeating the reduction cycle up to 1000 times (Figure 5). The reference compound, DTP showed significant changes to the reduction waves after only 400 cycles, highlighting the instability of this compound to repeated cycling. However, compounds TBTC, TNTC and TPTC all exhibit excellent stability to repeated cycling with no changes to the reduction profiles after 1000 repeated cycles. This emphasises that these materials are excellent candidates for stable electrochromic devices.
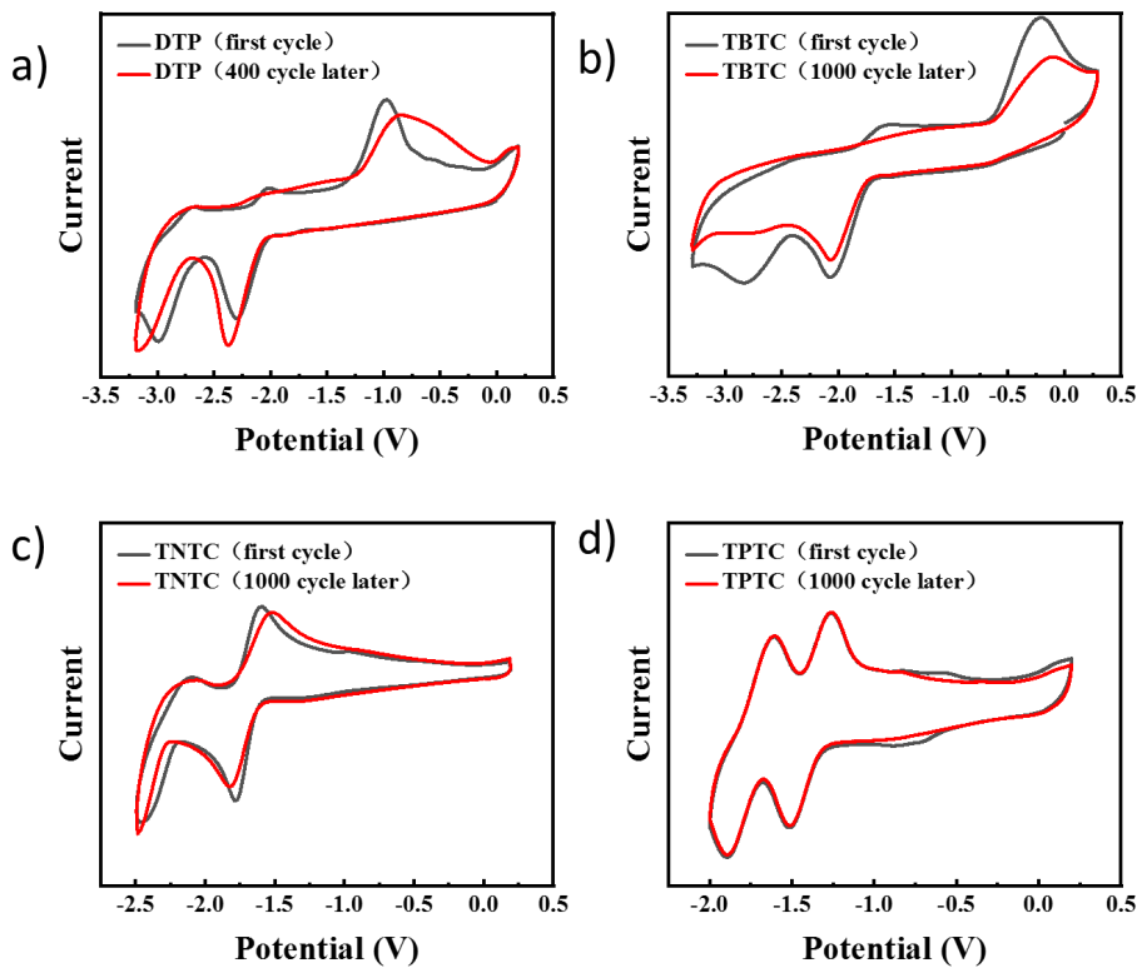

Figure 5. Stability of DTP, TBTC, TNTC and TPTC (1 mM and $5 \mathrm{mM}$ TPAP) in anhydrous DMF solution showing cyclic voltammograms. (CV: three-electrode system: WE-glassy carbon electrode; CE-Pt wire; RE-Ag/Ag+, scan speed: $100 \mathrm{mV} / \mathrm{s}$ ) 


\subsection{Conclusions}

New electrochromic single molecular systems, based on phthalates, were designed and synthesised based on a simple and scalable synthetic procedure. When tested by spectroelectrochemistry or used in EC devices the novel compounds showed vivid and reversible electrochromic behaviour with two separate reduction processes. Our study makes a breakthrough in lowering the driving potential $(-2.6 \mathrm{~V})$ of phthalate-based materials which also exhibit multicolour change characteristics, a good memory effect (over $400 \mathrm{~s}$ ), which can reduce the power required for electrochromism, and good stability. Interestingly, the area of the conjugated core of the molecules plays a critical role in obtaining different colours between redox states. We believe that our proposed design strategy can be the basis for development of further multi-electrochromic materials and the merits of phthalate series materials indicate their promising utilisation in industrial applications such as smart windows.

\subsection{Acknowledgement}

This work was financially supported by National Natural Science Foundation of China (51873002), the NSFC-PSF International Collaboration Project (51761145101), the NSFC-RS International Exchanges Project (5181102182), PSF-NSFC-II/Eng/C-IIUI (06), Royal Society/NSFC International Exchanges China Programme, IECINSFC1181564, Shenzhen Peacock Plan (KQTD2014062714543296), Shenzhen Engineering Laboratory (Shenzhen development and reform commission [2016]1592), the Shenzhen Science and Technology research grant (JCYJ20170818085627721, JCYJ20170818085627903, JCYJ20160510144254604) 


\section{References}

1. K. Madasamy, D. Velayutham, V. Suryanarayanan, M. Kathiresan and K.-C. Ho, J. Mater. Chem. C, 2019, 7, 4622-4637.

2. D. T. Christiansen, A. L. Tomlinson and J. R. Reynolds, J. Am. Chem. Soc., 2019, 141, 3859-3862.

3. J. Zeng, H. Li, Z. Wan, L. Ai, P. Liu and W. Deng, Sol. Energy Mater. Sol. Cells, 2019, 195, 89-98.

4. J. H. Ko, H. Lee, J. Choi, J. Y. Jang, S. M. Lee, H. J. Kim, Y.-J. Koc and S. U. Son, Polym. Chem., 2019, 10, 455459.

5. A. Chaudhary, D. K. Pathak, M. Tanwar, P. Yogi, P. R. Sagdeo and R. Kumar, ACS Appl. Electron. Mater., 2019, 1, 58-63.

6. P. Shi, C. M. Amb, E. P. Knott, E. J. Thompson, D. Y. Liu, J. Mei, A. L. Dyer and J. R. Reynolds, Adv. Mater., 2010, 22, 4949-4953.

7. C. Schoot, J. Ponjee, H. Van Dam, R. Van Doorn and P. Bolwijn, Appl. Phys. Lett., 1973, 23, 64-65.

8. K. Nakamura, Y. Oda, T. Sekikawa and M. Sugimoto, Jpn. J. Appl. Phys., 1987, 26, 931.

9. G. Guirado, C. Coudret, M. Hliwa and J.-P. Launay, J. Phys. Chem. B, 2005, 109, 17445-17459.

10. B. Yao, F. Chen, H. Jiang, J. Zhang and X. Wan, Electrochim. Acta, 2015, 166, 73-81.

11. W. Qiao, J. Zheng, Y. Wang, Y. Zheng, N. Song, X. Wan and Z. Y. Wang, Org. Lett., 2008, 10, 641-644.

12. W. Sharmoukh, K. C. Ko, J. H. Ko, H. J. Nam, D.-Y. Jung, C. Noh, J. Y. Lee and S. U. Son, J. Mater. Chem., 2008, 18, 4408-4413.

13. W. Sharmoukh, K. C. Ko, S. Y. Park, J. H. Ko, J. M. Lee, C. Noh, J. Y. Lee and S. U. Son, Org. Lett., 2008, 10, 5365-5368.

14. K. Imaizumi, Y. Watanabe, K. Nakamura, T. Omatsu and N. Kobayashi, Phys. Chem. Chem. Phys., 2011, 13, 11838-11840.

15. Z. Wan, J. Zeng, H. Li, P. Liu and W. Deng, Macromol. Rapid Commun., 2018, 39, 1700886.

16. Q. Tang, L.-h. He, Y.-h. Yang, J.-f. Long, X.-K. Fu and C.-b. Gong, Org. Electron., 2016, 30, $200-206$.

17. J.-f. Long, Q. Tang, Z. Lv, C.-r. Zhu, X.-k. Fu and C.-b. Gong, Electrochim. Acta, 2017, 248, 1-10.

18. S. Tanaka, Y. Watanabe, T. Nagashima and N. Kobayashi, Sol. Energy Mater. Sol. Cells, 2009, 93, $2098-2101$.

19. N. Kobayashi, S. Miura, M. Nishimura and H. Urano, Sol. Energy Mater. Sol. Cells, 2008, 92, 136-139.

20. E. D. Chenot, D. Bernardi, A. Comel and G. Kirsch, Synth. Commun., 2007, 37, 483-490.

21. M. Aleksiejew and J. R. Heldt, J. Lumin., 2007, 126, 665-676. 